\title{
Warning and Rehabilitation System Using Brain Computer Interface (BCI) in Cases of Bruxism'
}

\section{Sistema de alerta y rehabilitación de bruxismo utilizando una interfaz cerebro-computador (ICC) ${ }^{2}$}

\author{
César Augusto Peña-Cortés 3 \\ Óscar Eduardo-Gualdrón 4 \\ Gonzalo Guillermo Moreno-Contreras 5
}

DO1:10.11144/Javerlana.IYU18-1.SARB

\begin{abstract}
'Reception date on: May 24th, 2013. Acceptance date: July 26th, 2013. This paper results from the research project: Bruxism warning and rehabilitation system, code: SIARC-2012-I-Bruxism. Developed by the Research Group in Automation and Control and Research Group in Mechanical Engineering from the University of Pamplona, Pamplona, Colombia.

${ }^{2}$ Fecha de recepción: 24 de mayo de 2013. Fecha de aceptación: 26 de julio de 2013. Este artículo se deriva de un proyecto de investigación denominado Sistema de alerta y/o rehabilitación de bruxismo, código SIARC-2012-I-Bruxismo, desarrollado por el grupo de investigación Grupo de Automatización y Control-Grupo de Investigación de Ingeniería Mecánica de la Universidad de Pamplona, Pamplona, Colombia.

${ }^{3}$ Ingeniero electromecánico, Universidad Pedagógica y Tecnológica de Colombia, Tunja, Colombia. Maestría en Ingeniería Electrónica y de Computadores, Universidad de los Andes, Bogotá, Colombia. PhD en Automática y Robótica, Universidad Politécnica de Madrid, España. Profesor asociado, Universidad de Pamplona, Pamplona, Colombia. Correo electrónico: cesarapc@unipamplona.edu.co.

${ }^{4}$ Ingeniero electrónico, Universidad de Pamplona, Pamplona, Colombia. PhD en Electrónica, Universidad Rovira i Virgili, Tarragona, España. Profesor asistente, Universidad de Pamplona. Correo electrónico: oscar.gualdron@unipamplona.edu.co. ${ }^{5}$ Ingeniero mecánico, Universidad Francisco de Paula Santander, Cúcuta, Colombia. Maestría en Ingeniería Mecánica, Universidad de los Andes, Bogotá, Colombia. Profesor asistente, Universidad de Pamplona, Pamplona, Colombia. Correo electrónico: gmoren@unipamplona.edu.co.
\end{abstract}


178 César Augusto Peña-Cortés, Óscar Eduardo-Gualdrón, Gonzalo Guillermo Moreno-Contreras

\section{$\Delta \nabla \nabla$}

This research proposes a Bruxism rehabilitation system designed to achieve recovery without the need of mouth devices which tend to be annoying to patients. The system is based on the capture of neural signals by detecting brain activity related to Bruxism processes. For the detection of these events, we used an easy access, commercial, low-price Brain Computer Interface (BCI). The rehabilitation system generates an alert sound that prevents the patients' teeth to wear down during the hours of sleep without awakening them.

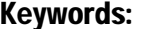

Bruxism, neuroscience, brain computer interface (BCI), brain control interface (BCI)

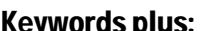

Bruxism, neurosciences, instrumentation

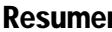

Este artículo propone un sistema de rehabilitación diseñado para pacientes que sufren de bruxismo, con el fin de que se recuperen sin necesidad de utilizar dispositivos dentro de la boca, los cuales suelen ser molestos para quienes los usan. El sistema está basado en la captura de neuroseñales que detectan la actividad cerebral correspondiente a eventos del bruxismo. Para la detección de estos eventos se empleó un dispositivo comercial BCI de fácil adquisición y bajo precio. El sistema de rehabilitación genera una alerta sonora que impide el desgaste de los dientes a los usuarios sin llegar a despertarlos.

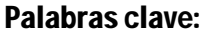

Bruxismo, neurociencia, instrumentación y control cerebral

\section{士}

Bruxismo, neurociencias, instrumentación 


\section{Introduction}

According to the journal published by the Society of Odontostomatology in Santiago, Chile, bruxism can be defined as an oral para-functional activity consisting in the clenching and gnashing of the teeth -the study of the causes, Etiology- with their multi-factors and they are associated, principally, to stress and the alterations during the hours of sleep or parasomnia (Gonçalves, Toledo, and Otero, 2010). Different types of bruxism can be present depending on the clinical characteristics of it. It appears to be more common among adults, although it can also be present among children. This differential occurrence is probably due to the differences in physiological deterioration observed in this older part of the population (Frugone y Rodriguez, 2003).

\section{Background}

Bruxism or dental stress is a disorder or condition that produces dental deterioration and goes hand in hand with occlusion. According to several investigations this affliction is based mainly on psychic burdens, emotional tension, anguish, frustration among other difficulties (Gómez, 2001). In the investigation of some medical reports (Pérez et al., 2002; Martínez et al., 2012; Jaen, 2012) it has been found that every human being experiments a few periods of nocturnal bruxism throughout life but that only between $5 \%$ and $20 \%$ of the world population shows chronic bruxism.

Out of this percentage of the world population, only 20 to $30 \%$ realize they are suffering from bruxism. This can be compared to medical conditions such as hypertension and diabetes. These people with bruxism do not realize they even have this difficulty until a doctor or an expert reviews this situation; also, in a catastrophic manifestation it is usually too late to do anything by the time the condition is recognized (Sacoto, 2012; Delgado and Pujol, 1996).

Other studies done with children with an average age of 8 years old in Brazil have shown that bruxism is an illness present, in the majority of cases, at low socio-economic levels, results indicated that $35.3 \%$ exhibited symptoms related 
to Bruxism during the hours of sleep and mainly, in girls (56.5\%) (Dela and Queiroz, 2006; Serra et al., 2012).

Bruxism can persist even into the adult age. It appears that there are no differences by sex in occurrence of this condition among adults; and 1 out of 5 patients with bruxism shows symptoms of oral facial pain. Some studies show that the highest prevalence of this affection would be among Asians; that Europeans, North Americans and Hispanics would have lower prevalence than Asians; and that the lowest prevalence would be found among African-Americans (Sacoto, 2012; Moncada et al., 2009).

\section{The interface used in the detection of bruxism}

There are various investigations that have attempted to develop devices to avoid Bruxism, which have different characteristics. One of the most recent and significant developments uses electrical piece polymers (Martínez et al., 2010; Jung et al., 2010); others use prevention devices based on tweezers or pressure sensors (De Macedo, 2007; Gonzalez and Lantada, 2009; Sakai et al., 2004); and others are based on electromyographic instruments (Palumbo et al., 2007). One of the main problems with most of these developed systems is that they generate discomfort in patients because they require patients to sleep with instruments within their mouths.

Within the past few years, there has been important investigation in neuroscience. Many groups in different countries have understook projects to develop mathematical models about brain behavior to understand brain disorders explaining a great quantity of illnesses (Egan, 2004).

One of those projects, the most relevant in this area, is the Connectome. This project aims to create a map of the connections to the neurons in the brain, which could have a great impact on the understanding of illnesses such as Alzheimer's disease (Jaume et al., 2012). Thanks to these advances, some technological devices have been generated. These devices have permitted the capture, processing and interpretation of neural-signals.

The present study proposes the use of a BCI (Brain Computer Interface) device to detect brain activities concerning bruxism. This type of device has been created based on electroencephalograms (EEG's) centered on the neural-physiological exploration by means of records of bioelectrical activity of the brain. So far, commercial methods or tests have been conducted with this type of technology. Some of the most important examples are the Neurosky Interactive Productline, Xwave, BrainAmp and the Emotiv EPOC (Alzu'bi, Al-Zubi y Al-Nuaimy, 2011). 
The BCI device based on EEG's is equipped with one sensor that is placed in the left ear of the patient with its respective ground reference signal and wireless Bluetooth communication systems which allows for mobility and acquisition velocity up to $512 \mathrm{~Hz}$. In recent years a variety of articles have been generated that employ this technology with the Neurosky devices (An Luo and Sullivan, 2010; Crowley et al., 2010). Other interesting and novel devices have been produced by the Interactive Productline Company. These devices allow realtime signal capturing of brain activities. Their main product 'the Mindball' is employed for sports training, for therapy and for educational institutions. The Company PLX Devices has developed the XWAVE to manage the Apple iPad, iPhone and iPod touch equipment without having to touch the screen and using the NeuroSky technology. This method is based on sensors measuring brain activity by placing one of the sensors on the earlobe in order to attain the action of the pulse. Thanks to this mechanism it is possible to control applications or even games with the Apple equipment. The XWave connects to the Apple devices through the headphone input using an application designed by PLX. One of the applications designed by the Company allows to levitate a virtual ball or a mediator that establishes the level of attention or relaxation of the user.

The article is organized in the following way: in section 1, the problematic of bruxism and its causes with conventional treatments; section 2 contains the device of alert and/or rehabilitation proposed and in section 3, the analysis of the obtained results are given. In section 4 the conclusion of the investigation and lastly, Bibliographical references.

\section{Bruxism}

\subsection{Research problem}

Many theories have tried to explain the etiology of bruxism in these past few years; nonetheless, the majority of ideas suggest that it is related to multiple factors. The involved factors can be classified between peripheral and central factors as well. These can include: Morphological, patho-physiological and psychological factors.

Figure 1 corresponds to a patient with an advanced level of bruxism. Due to the condition, the patient has lost a great part of the dental crown; also, this patient has a marked divergence of the gums. 
Figure 1. Patient with advanced bruxism

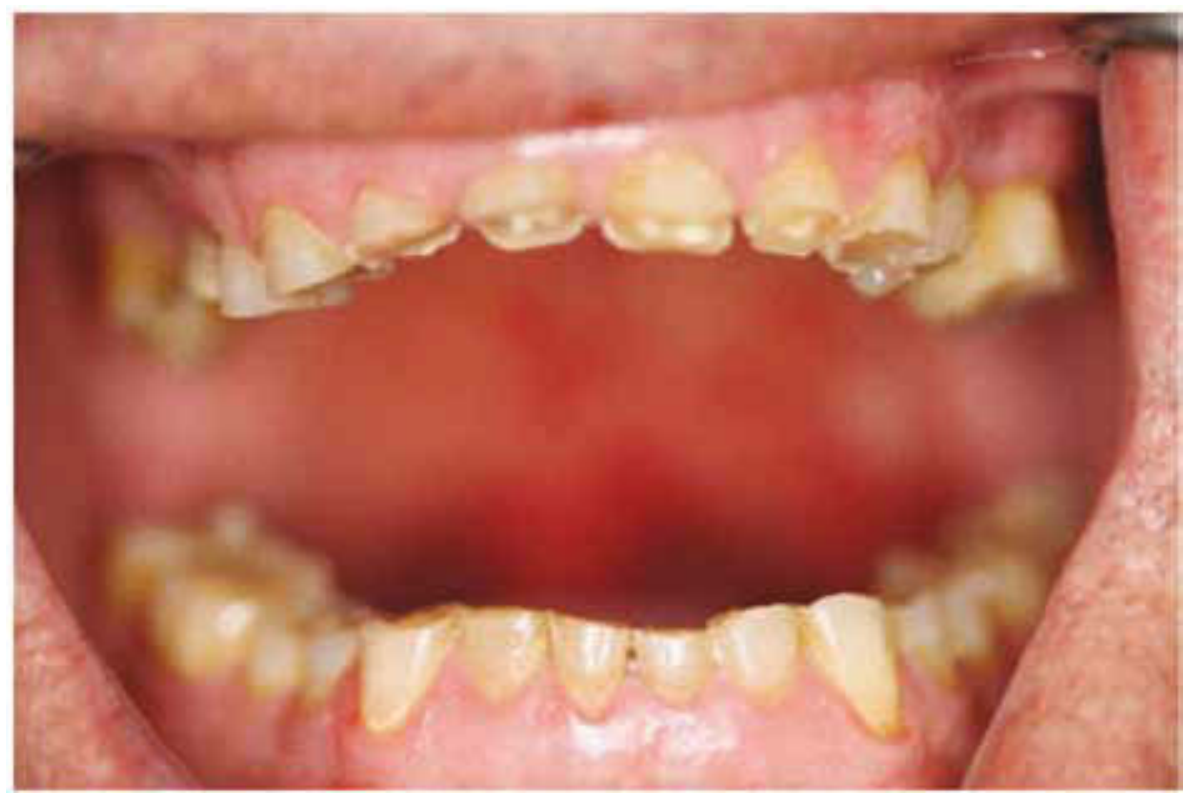

Source: Taken from (Rey, 2010).

\subsection{Causes of bruxism}

As it has already been mentioned, three factors can be related to the etiology of bruxism. These factors may relate to each other, and what is certain is that there is a growing body of research on the topic.

The morphological factors refer to the alteration of the dental occlusion and to abnormalities of the joint and bone. The patho-physiological aspects are related to the fact that Bruxism mainly occurs during the hours of sleep, which is an aspect that has received great attention. The psychological aspects refer to the belief that psychological stress contributes to the physio-pathology in bruxism. The potential contribution of stress has been proposed as studies have shown an increased electromyographic activity of the mastoid muscle during sleep after episodes of physical or emotional stress experienced by persons. However, there is still a need for controlled studies that allow ascertaining the true contribution of psychological aspects to bruxism during sleep (Frugone and Rodriguez, 2003).

\subsection{Conventional treatments}

The experts on Bruxism coincide that the treatment for the suffering of this illness should be multi-disciplined and not only oriented to one of the possible causes. 
The psychology could complement this treatment in a valuable way towards the orthodontia cure in order to obtain very good results in the rehabilitation.

Figure 2 shows a device used to prevent bruxism. The device consists of a pair of retainers linked by a lever placed in a diagonal way and that impedes the patient's clenching of the teeth. This treatment is often called 'the pattern of the bite'.

Figure 2. Device for the treatment of bruxism

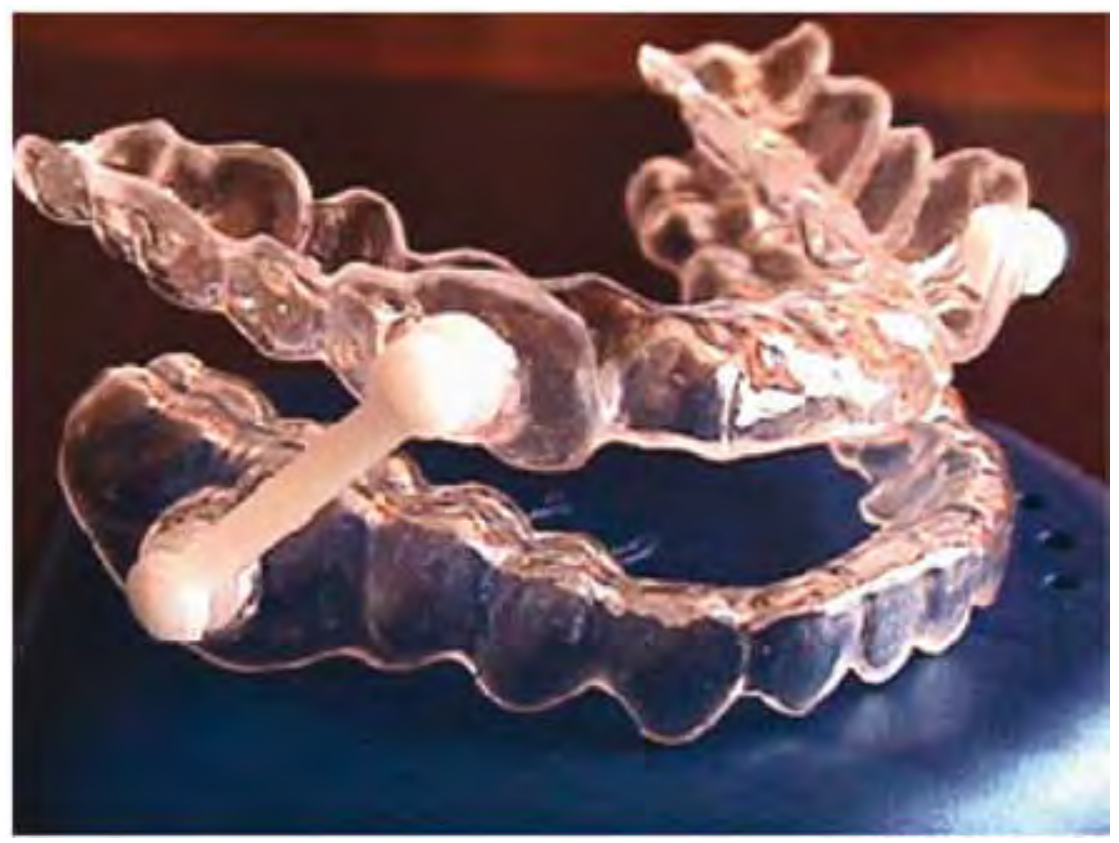

Source: Taken from (Consejos Naturales, s.f).

Some people could be benefited with an occlusion adjustment or 'pattern of the bite'. The areas that could be generating a bad 'bite' of the upper and lower jaws may cause friction or forces that are uncomfortable for the patient. The treatment could also include the movement of harmful contacts among some of the dental pieces that are establishing the 'bite'. In these cases in which bruxism is so severe that it causes damage to the teeth, the person might be helped with a 'bite-plate' or protector of the teeth (an acrylic piece of about 2 or 3 millimetres thick) preventing the upper and lower teeth to make contact during the night hours when bruxism appears (Revista Buena Salud, 2009). 
Only in extreme cases would pharmaceutical treatment be recommended, such as: muscular relaxers and sleeping pills that are used to avoid the patient from worsening that condition (Palazón, Berrocal, and Cabañas, 2001). Other alternative treatments exist and are in the process of being investigated, such as: subjecting the myofacial and muscular energy areas that are applied to the bilateral mastoid (Cejo and Legal, 2011).

\section{Device of alert and/or proposal for rehabilitation}

Given that the majority of instruments used in the rehabilitation of bruxism is based on the use of mouth pieces and piezoelectric devices, we propose the use of an interface capturing high resolution neural signals to detect the movements caused by this disease.

One of the main disadvantages experienced by patients using traditional instruments for bruxism is the discomfort of wearing plastic mouth pieces with internal sensors and circuits. The advantage of the use of an interface with neuro-signals is that its use is external, so the patient discomfort will be largely reduced.

\subsection{Interface with high resolution of neural-signals}

Today the development of brain interfaces is a reality at both research and commercial level. One of the most relevant interfaces has been developed by the company Emotiv, which, at a low cost and based on neural-technology, has developed a personal interface of human-computer interaction. Figure 3 shows the interface with 16 sensors that capture neural signals and a person using it.

Figure 3. Interface capturing the neural-signals of high resolution (Emotiv Headset)
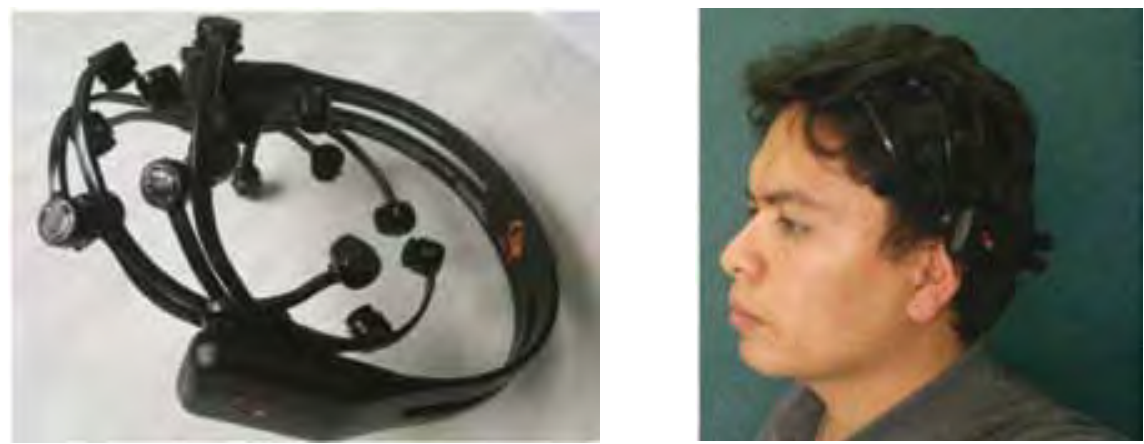

Source: Authors' own presentation. 
This interface is very light-weight, flexible and has a wireless communication system, which is why it would not generate any significant discomfort in the patients. Although most applications of this interface have been designed for computers, they can also be used in smart phones (Stopczynski et al., 2011) to be operated by patients themselves. The size of these interfaces is becoming smaller, so in the very near future there will be interfaces minimally perceivable by users.

Figure 4 shows the distribution of 16 sensors on the patient's skull. This distribution reflects the main signals generated by the brain, in which small gestures can be estimated, such as: a wink, a frown, closing an eye, among others. In addition, it is also possible to measure emotions that reflect a bit of excitement, a state of calmness, meditation, distraction or concentration.

Figure 4. Sensors distribution scheme

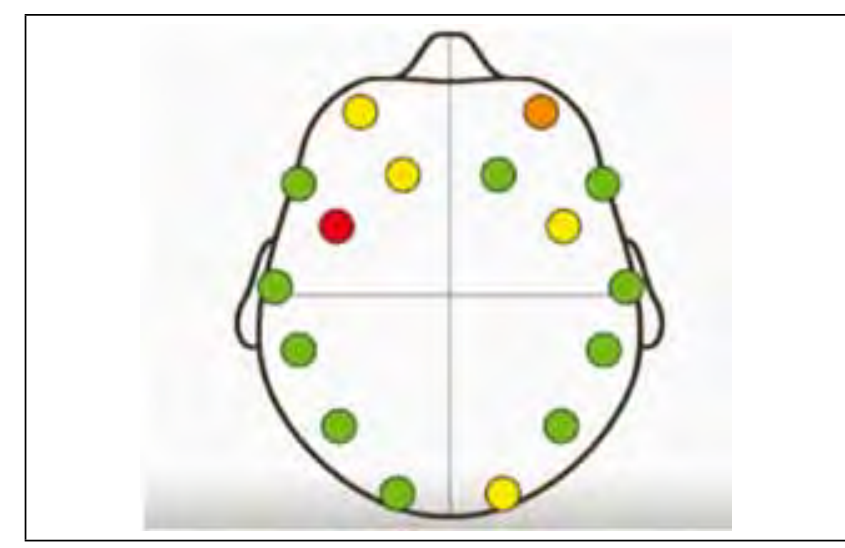

Source: Authors' own presentation.

Produced by means of EPOC Panel Control (Expresiv Suit).

Each gesture or emotion produced activates one or various zones of the brain. Basically the interface is responsible for capturing the delta $(1-4 \mathrm{~Hz})$, theta (4-7 Hz), Alpha $(7-13 \mathrm{~Hz}$ ) and beta waves $(13-30 \mathrm{~Hz})$. Figure 5 shows the brain areas that are activated when bruxism occurs. In this case the Beta waves are captured; they are of greater relevance when a movement occurs. It is noteworthy that the various gestures provoked by teeth grinding are characterized and identified by its high dominance and sturdiness, much like the head movements. 
Figure 5. Map of brain activity - Beta Waves $13-30 \mathrm{~Hz}$

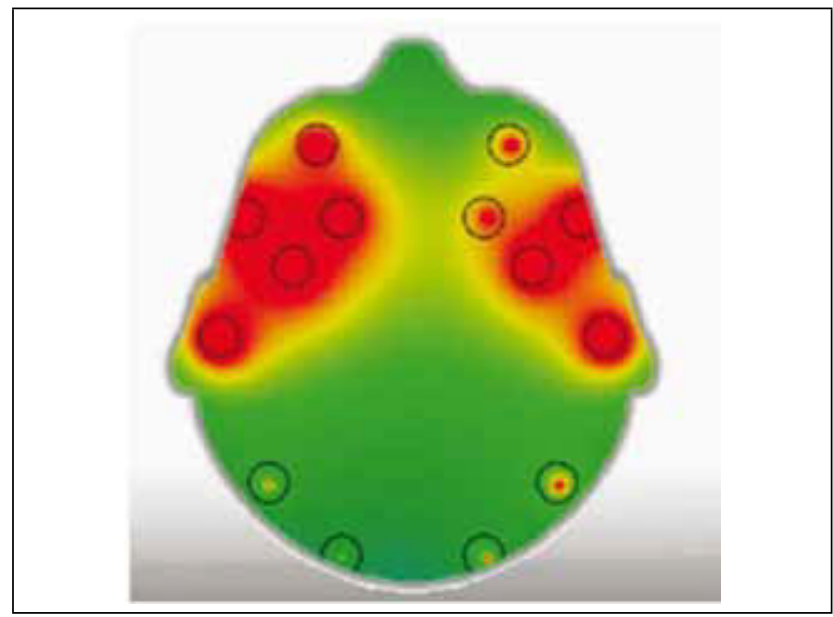

Source: Authors' own presentation. Generated through the Emotiv Brain Activity Map.

Figure 6 shows an example where neural signals, present in bruxism, are recognized. Figure 6 shows (a) the patient at rest or normal state and Figure 6 shows (b) the patient exerting pressure on the jaw.

Figure 6. Detection of the force exerted by the jaw
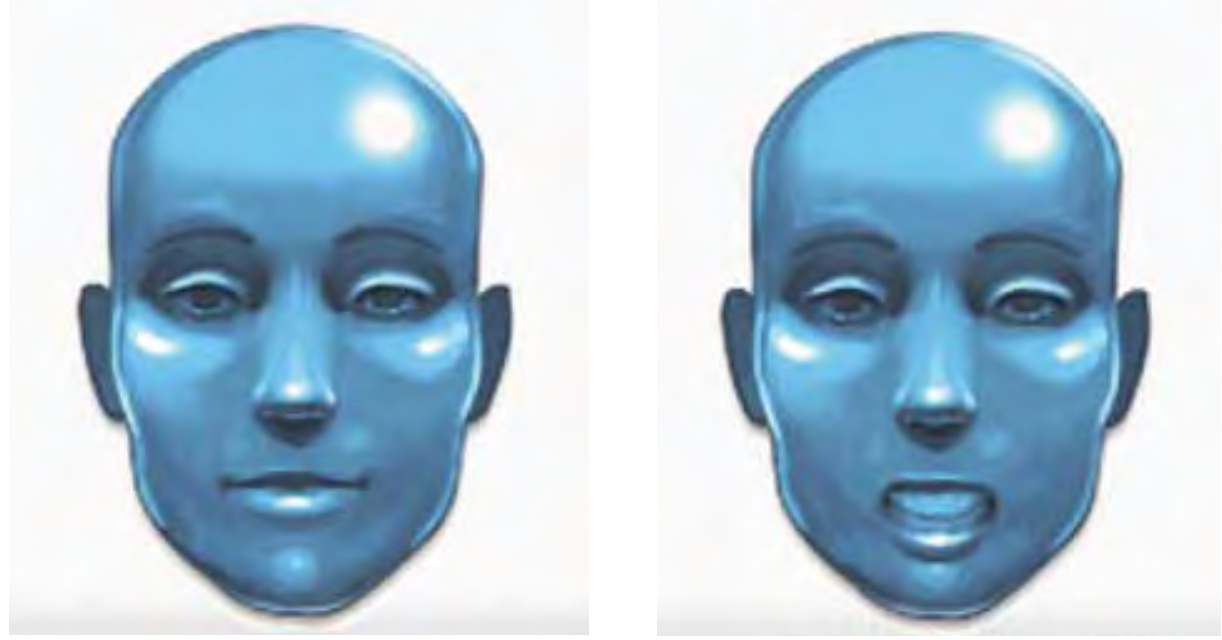

(a) Normal state; (b) Force exerted by the jaw Source: Authors' own presentation by means of EPOC Panel Control (Expresiv Suit). 
An advantage of using the Emotiv EPOC device is the high resolution in capturing neural signals. This feature distinguishes relatively similar gestures from each other. One example is smile, laughter, moving the mouth towards the left and towards the right. It was not necessary to apply additional algorithms of signals processing when using the interface EPOC, produced by the company Emotiv. This is because it has software that captures, through training, different types of patterns. These patterns are classified as emotional, expressive and affective. The idea for this project came about through experiments performed with this interface, which reflected a higher strength when teeth grinding occurred, compared to other events, without the need of previous training. Considering that bruxism is characterized by the excessive grinding of teeth, we decided to create this warning system. Moreover, the boom that have had this kind of interfaces has favored the production of large quantities of them, which substantially reduces its costs. In the near future, due the commerce of small mobile interfaces (interfaces connected to mobile phones via bluetooth, reduced in size), this type of system can be implemented.

\subsection{Algorithm operation}

The general idea of the proposed algorithm is that when the patient is asleep, and begins to produce the movements caused by bruxism, a device (computer or mobile phone) will emit a sound signal that will help the patient to realize the unconscious movement he/she is making, and thus avoid it. The audio signal varies according to the frequency with which the movement of the jaw occurs. If the patient makes very strong movements, the signal will repeat with a relevant frequency; it will decrease as he/she stop these movements. Patients can graduate sound volume, as well as the sensitivity with which their jaw movements are detected to avoid being awakened, all this in order to undergo therapy at the unconscious level, undisturbed.

Figure 7 shows the flow chart of the computational algorithm that was implemented. First, the high resolution neural signals are captured, then, they are analyzed to determine if these signals correspond to dreams (cognitive and / or affective signals) or if the patient is making gestures derived from them (expressive signals). If patient makes a gesture, it is analyzed and classified as derived from bruxism or not (depending on the area of the brain that is activated). If it is classified as bruxism, a sound signal is generated, which alerts the patient to stop the movement. Finally, a verification of the deactivation of the system 
to end the algorithm or not is performed. In case of being negative, the cycle continues capturing neural signals.

Figure 7. Flowchart of the algorithm

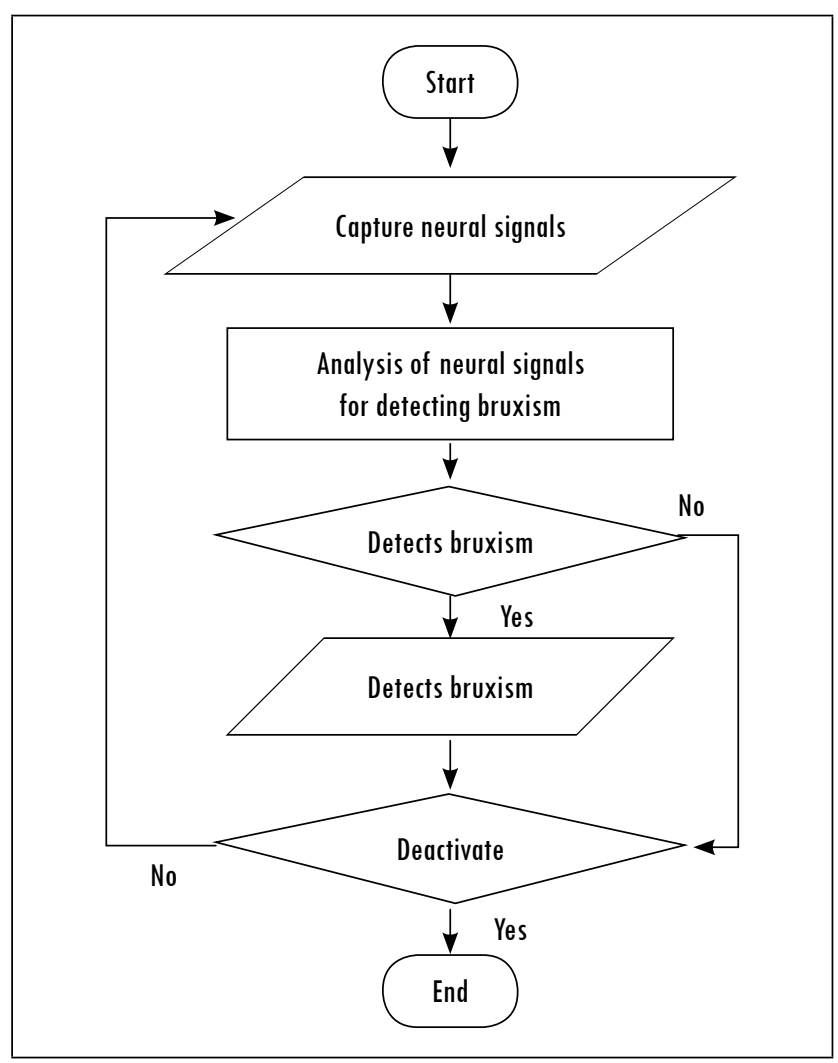

Source: Authors' own presentation.

Another possible signal that the system might employ to warn users of the movements caused by bruxism, is through a vibration device, similar to those implemented in cell phones. This second alternative may be implemented in cases where users sleep with someone, and don't want to disturb the other person.

\section{Analysis of results}

To confirm the proper functioning of the proposed system, two types of experiments were performed with 10 users. In the first experiment, using only the 
BCI interface, users were asked to verify if a sound signal reproduced when they clench their teeth. In all cases, users reported that as soon as they began to force their jaw, the sound warning signals of bruxism were activated.

Figure 8 shows the results of the experiment where the system sound signals were deactivated. Users were asked to introduce a fairly noisy plastic piece in their mouths for the sound to be heard by a microphone located near their lips, and we could hear the sounds caused by grinding their teeth. In this graph we can see the sound produced by both plastic and markers, indicating the activation of neural signals related to bruxism, which correspond accordingly/properly, allowing the system verification.

Figure 8. Detection of bruxism events and sound verification

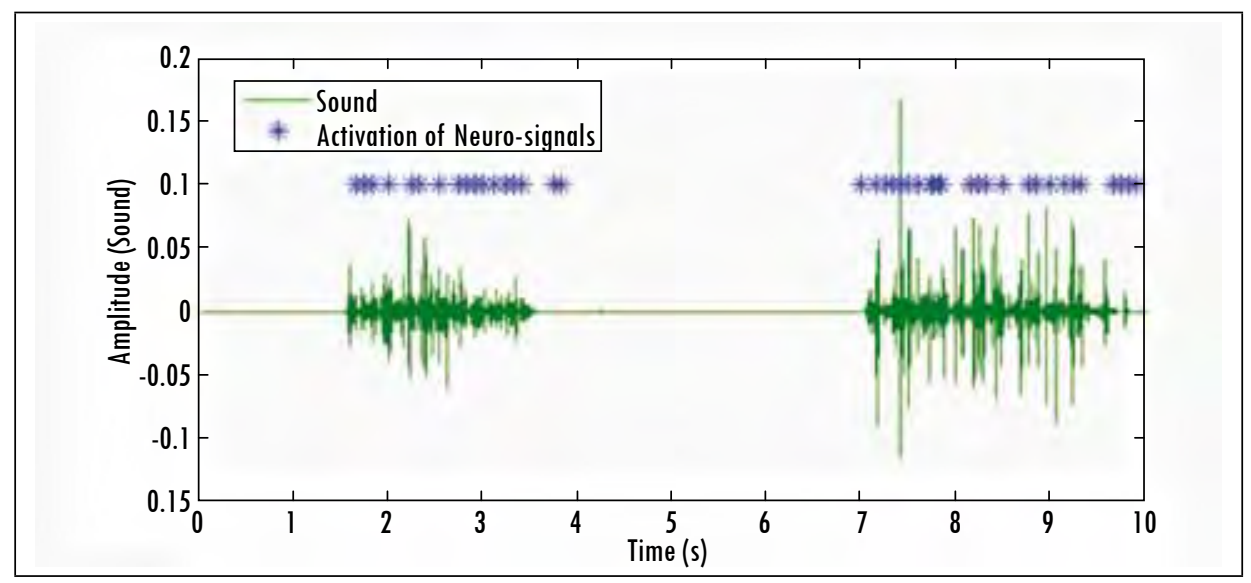

Source: Authors' own presentation.

For a second method of verification, a design was made using a force sensor (Flexiforce A201). This sensor was placed in the middle of two sheets of acetate $(0.8 \mathrm{~mm}$ thick) with a plastic cover to prevent damage. This device was positioned on the molar teeth of 10 users. During the experiment, users were asked to do consecutive bites for 20 seconds. It is worth noting that detection was successful in all cases.

Figure 9 shows the results of one experiment. We can observe that both signals (bite and force) were normalized for comparison. The signal generated by the $\mathrm{BCI}$ is almost simultaneously activated with the signal generated by the force sensor. 
Figure 9. Detection of events of bruxism and verification using a force sensor

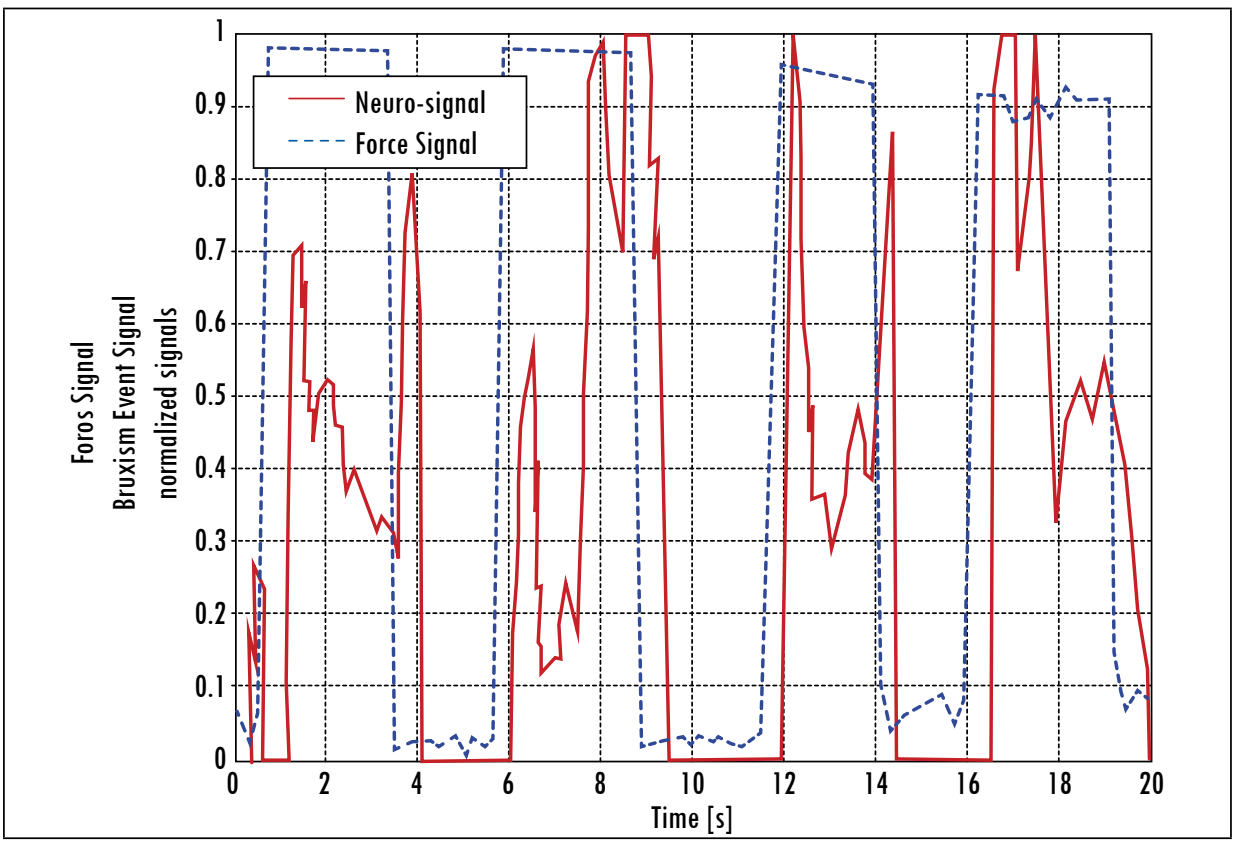

Source: Authors' own presentation.

In addition to these experiments, a test was conducted in a patient with problems of daytime bruxism; he used the system for 4 hours. For this, he/she conducted his/her daily tasks of a working day. The user expressed a positive attitude towards the system because it made him realize when he was grinding his teeth. It should be noted that, in order to avoid activation of alerts under common movements, user changed the levels of detection (under the detection threshold). This is a common problem in daytime bruxism

\section{Conclusions}

The alert and rehabilitation system, based on the interface that captures neural signals, works fine; this was verified by both experiments conducted to detect the events associated to bruxism. This method represents an alternative treatment to this problem.

Given the effectiveness of the system, it could serve as a tool for early diagnosis of this type of disease. Moreover, the frequency of occurrence can be quantified in patients, and it can generate and / or feed the epidemiology databases 
Experiments conducted for the system verification, using the force sensor, proved a $100 \%$ of successful detection of teeth grinding. However, the limitation of the system is that it needs a continuous sensor maintenance (cleaning) every 10 hours.

Since the main problem of bruxism is tooth wear, the proposed system works as an alternative to detect this disease. It is expected that the characteristics of the new BCI devices under development (such as, greater autonomy, smaller size, reduced number of sensors and, particularly, the connection to mobile phones and networks), could implement the proposed algorithm. This could provide greater comfort to users.

Additionally, in the future, the use of this device could help detect the concentration, frustration and emotional levels, as events or symptoms related to this disease.

The neural-signals correspond to the force produced in the jaw and these are easily detected; therefore, these neural-signals with their sensors can be used as an instrument of control in disabled individuals such as quadriplegic patients. This would help them control their wheelchairs or even in communication systems.

\section{References}

ALZU'BI, H.S.; AL-ZUBI, N.S., and AL-NUAIMY, W. Toward inexpensive and practical brain computer interface. Developments in E-systems Engineering (DeSE). 2011, pp.98-101.

CEJO, P. and LEGAL, L. Effects of the myofascial anchorage and muscular energy techniques in patients with bruxism. Revista Osteopatía Científica. 2011, vol. 6, no. 2, pp. 46-52.

CONSEJOS NATURALES. El bruxismo [document en línea]. http://www.consejosnaturales. com/el-bruxismo.html.

CROWLEY, K.; SLINEY, A.; PITT, I. and MURPHY, D. Evaluating a brain-computer interface to categorize human emotional response. IEEE International Conference on Advanced Learning Technologies. 2010, pp 276-278.

DE MACEDO, C. Placas oclusais para tratamento do bruxismo do sono: revisão sistemática Cochrane. Sao Paulo: Universidade Federal do São Paulo, 2007.

DELA, K. and DE QUEIROZ, J. Bruxismo na infância: fatores etiológicos e possíveis tratamentos. Revista de Odontologia da UNESP. 2006, vol. 35, no. 2, pp. 157-163.

DELGADO, M. and PUJOL, T. Infantile bruxism: an alarm signal. Revista Aten Primaria. 1996, vol. 17 , no. 2, 172-173.

EGAN, G.F. Neuroinformatics: development of shared neuroscience databases and tools at the Australian National Neuroscience Facility. Proceedings 2004 IEEE International Joint Conference on Neural Networks. 2004, vol. 1, pp. 25-29. 
FRUGONE, R. and RODRIGUEZ, C. Bruxismo. Av Odontoestomatol [online]. 2003, vol. 19, no. 3, pp. 123-130.

GÓMEZ, F. Can bruxism be useful the central nervous system to reduce stress? Gaceta Médica Bilbao. 2001, vol. 98, no. 4, pp. 113-116.

GONZÁLEZ, C. and LANTADA, A.D. A wearable passive force sensor powered by an active interrogator intended for intra-splint use for the detection and recording of bruxism. Pervasive Computing Technologies for Healthcare, 2009. Pervasive Health 2009. 3rd International Conference on, IEEE. 2009, pp.1-4.

GONÇALVES, L.P.; TOLEDO, O.A. and OTERO, S.A. Relação entre bruxismo, fatores oclusais e hábitos bucais. Dental Press Journal of Orthodontics. 2010, vol. 15, no. 2, pp. 97-104.

JAEN, F. El bruxismo, un mal que casi todos padecemos [document on line]. < http://www.saludpanama.com > [Cited: 04-06-2012].

JAUME, S.; KNOBE, K.; NEWTON, R.R.; SCHLIMBACH, F.; BLOWER, M. and REID, R.C. A multiscale parallel computing architecture for automated segmentation of the brain connectome. IEEE Transactions on Biomedical Engineering. 2012, vol. 59, no. 1, pp. 35-38.

KIM, J.H.; MCAULIFFE, P.; O'CONNEL, B.; DIAMOND, D.; LAU, K.T. Development of bite guard for wireless monitoring of bruxism using pressure-sensitive polymer. International Conference on Body Sensor Networks (BSN). 2010, pp. 109-116.

LUO, A. and SULLIVAN, T.J. A user-friendly SSVEP-based brain-computer interface using a time-domain classifier. Journal of Neural Engineering. 2010, vol. 7, no. 2, p. 26010.

MARTÍNEZ, A.; BARRIENTOS, A.; DÍAZ, A.; LAFONT, P.; COLORADO, J.; CASTEDO, P.L. and GONZÁLEZ, R. Polymeric piezoelectric sensors and remote communication for detection of bruxism. International Conference on Industrial Technology (ICIT), 2010 IEEE. 2010, pp. 268-273.

MARTÍNEZ, I.; TOlEDO, B.; PRENDES, T.; CARVAJAL, A.; DElGADO, T. and MORALES, A. Risk facts in patients with temporomandibular dysfunction. Revista Médica Electrónica. 2009.

MONCADA, L.; GALLARDO, I.; AGUILAR, L.; CONEJAN, C.; DREYER, E. and ROJAS, G. Bruxers presents a distinctive style of personality. Revista Chilena de Neuro-Psiquiatría. 2009, vol. 47, no. 2, pp. 105-113.

PALAZÓN, R.; BERROCAL, I. and CABAÑAS, J. Treatment of bruxism with botulinim toxin. Revista Rehabilitación. 2001, vol. 35, no. 4, pp. 253-255.

PALUMBO, A.; PACE, C.; FARELlA, M. and COCORUllO, G. An example of System on Chip design for biomedical applications: bruxism therapy. Instrumentation and Measurement Technology Conference Proceedings. 2007, pp. 1-3.

PÉREZ, M.; LEMUS, L.; ALMAGRO, S. and ROBLEDO, M. Rehabilitación protésica del bruxismo en el adulto. 16 de Abril. Revista Cubana de los Estudiantes de Ciencias Médicas 
[online]. 2002, vol. 41, no. 1. <http://bvs.sld.cu/revistas/abr/vol41_1_02/abr05102. htm > [Cited: 04-05-2012].

REVISTA BUENA SALUD. Soluciones para quienes padecen bruxismo [article online]. 2009. $<$ http://www.revistabuenasalud.com/bruxismo-soluciones-para-quienes-rechinan-losdientes-al-dormir/> [Cited: 2012-04-20].

REY, A. Bruxismo. Diagnóstico control [document online]. 2010. < http://antonioreygil.blogspot. com/2010/06/el-bruxismo-es-considerado-un-trastorno.html > [Cited 04-20-2012].

SACOTO, M. Estadística sobre el bruxismo en adultos y niños [document online]. $<$ http://mariansacotonavia.com $>$ [Cited: 04-04-2012].

SAKAI, R.; YOSHIDA, H.; KAWAHATA, N.; KIKUCHI, M. and NAKAJIMA, I. Realization of anterior guidance with canine and occlusion by a mastication motion simulator. SICE 2004 Annual Conference. 2004, vol. 2, pp. 1715-1720.

SERRA, J.; PAIVA, S.; SEABRA, A.; DORELLA, C.; LEMOS, B. F. and PORDEUS, I.A. Prevalence of sleep bruxism in a group of Brazilian school children. European Archives of Paediatric Dentistry. 2010, vol. 11, no. 4, pp. 192-195.

STOPCZYNSKI, A.; LARSEN, J.; STAHLHUT, C.; PETERSEN M. and HANSEN, L. A smartphone interface for a wireless EEG headset with real-time 3D reconstruction. Affective Computing and Intelligent Interaction. 2011, pp. 317-318. 
